\title{
Arp2/3 Complex Is Expressed in Oral Squamous Cell Carcinoma: An Immunohistochemical Study of 88 Cases
}

\author{
Marina P. Georgopoulou ${ }^{1 *}$, Konstantinos I. Tosios ${ }^{2}$, Nikolaos Goutas ${ }^{1}$, Mirsini Kouloukoussa ${ }^{3}$ \\ ${ }^{1}$ Department of Forensic Medicine and Toxicology, Medical School, National and Kapodistrian University of Athens, Athens, Greece \\ ${ }^{2}$ Department of Oral Medicine and Pathology, Faculty of Dentistry, National and Kapodistrian University of Athens, Athens, Greece \\ ${ }^{3}$ Department of Histology and Embryology, Medical School, National and Kapodistrian University of Athens, Athens, Greece \\ Email: *stomatologos2004@yahoo.gr
}

How to cite this paper: Georgopoulou, M.P., Tosios, K.I., Goutas, N. and Kouloukoussa, M. (2019) Arp2/3 Complex Is Expressed in Oral Squamous Cell Carcinoma: An Immunohistochemical Study of 88 Cases. Open Journal of Stomatology, 9 , 29-38.

https://doi.org/10.4236/ojst.2019.93004

Received: February 3, 2019

Accepted: March 4, 2019

Published: March 7, 2019

Copyright $\odot 2019$ by author(s) and Scientific Research Publishing Inc. This work is licensed under the Creative Commons Attribution International License (CC BY 4.0).

http://creativecommons.org/licenses/by/4.0/

(c) (i) Open Access

\begin{abstract}
Background: We investigated the immunohistochemical expression of Arp2/3 complex in 88 oral squamous cell carcinomas (OSCCs) and correlated it with the tumor type and grade. Materials and methods: This is a retrospective study of 88 cases of OSCCs (9 verrucous carcinomas, 4 carcinomas in situ, 37 well differentiated OSCCs, 32 moderately differentiated OSCCs, and 6 poorly differentiated OSCCs), stained with mouse monoclonal antibodies for Arp2 and Arp3. Staining was graded according to the extent of positivity by two observers. Results: Arp2 positivity was seen in 79 (89.77\%) cases and Arp3 positivity in $78(88.63 \%)$ cases. In positive cases, Arp2 expression was graded as $(+)$ in $12.5 \%,(++)$ in $28.4 \%$ and $(+++)$ in $48.86 \%$ of the cases; Arp3 was graded as $(+)$ in $36.36 \%,(++)$ in $30.68 \%$ and $(+++)$ in $21.59 \%$ of the cases. Conclusion: Expression of Arp2 and Arp3, indicative of the formation of the Arp $2 / 3$ complex, was seen in most OSCCs examined. Although no statistically significant correlation was found between the immunohistochemical expression of Arp2/Arp3 and tumor type or grade, the more common expression in invasive OSCCs than in non-invasive verrucous carcinomas and carcinomas in situ is indicative of its involvement in the biological behaviour of the lesions. The availability of Arp2/3 inhibitors that could be used in clinical practice warrants further study of the expression of Arp2/3 in OSCC.
\end{abstract}

\section{Keywords}

Actin-Related Protein 2-3 Complex, Squamous Cell Carcinoma, Oral

\section{Introduction}

Oral cancer is one of the 10 most common cancers and despite progress in di- 
agnosis and treatment survival has not improved significantly during the last years [1]. Prognosis and survival are associated with certain clinicopathological parameters, the most significant being regional and distant metastasis [2] [3]. However, metastatic behavior cannot be accurately predicted by histology or individual gene or protein expression/activity.

Metastasis requires motility of cancer cells [4]. The main types of cellular structures associated with motility that may have a role in the invasion process are filopodia, lamellipodia, invadopodia and podosomes, the latter two collectively known as invadosomes [5]. The formation and regulatory activities of these cellular "feet" are controlled by a variety of molecules with specific roles in their formation [5] [6]. Formation of filopodia, lamellipodia and invadopodia is driven by spatially and temporally regulated actin polymerization at the leading edge of migrating and invading cells [6]. This is associated with the actin related protein 2/3 complex (Arp2/3 complex), an activator of actin filament nucleation and branching [7] [8] [9] [10]. Several lines of evidence indicate that these proteins are necessary for cell movement associated with cell migration and invasion. Moreover, the expression Arp2/3 complex has been associated with malignant cell phenotypes, indicating the importance of these proteins in cancer cell migration and invasion [11]-[18].

The Arp2/3 complex consists of seven proteins with five unique subunits (ARPC1-5) forming the dimer Arp2/3 [19]. Cooperative interactions with ATP, nucleation promoting factors and the side chain of an actin filament activate Arp2/3 complex to initiate the production of a new actin filament [20]. However, silencing of any of the Arp2/3 complex subunits genes results in a significant decrease in the cell migratory capacity [11] [18]. Since the first report about its distribution in colorectal cancer [12], overexpression of Arp2/3 has been found in $56 \%$ to $91.8 \%$ of various malignant tumors, such as liver metastasis from colon primary carcinoma, breast, pancreatic, lung, gastric carcinoma and human gliomas [12]-[18] and has been associated with pathogenesis, growth and invasion in some of them [13] [14] [15] [16] [17]. In head and neck carcinomas, silencing of the ARPC5 gene that encodes one of the seven subunits of Arp2/3 complex led to changes in cell morphology, and suppression of cell migration and invasion [11]. However, expression of Arp2/3 in oral squamous cell carcinoma has not been previously investigated.

We investigated the immunohistochemical expression of Arp2/3 in 88 OSCCs and correlated it to tumor type and grade.

\section{Material and Methods}

This is a retrospective immunohistochemical study of 88 cases of oral carcinomas retrieved from the files of the Laboratory of Histology and Embryology, Faculty of Medicine, during the years 2005-2008 (approval no. 5171). All tissues were diagnostic biopsies resected at Athens University Hospital (clinic of Dermatology and Stomatology A. Syggros during these years) and fixed in $10 \%$ for- 
malin for $<24$ hours and embedded in paraffin (FFPE). Age and gender of the patients, as well asprimary location, were retrieved from the biopsy request form of each case, where available. Hematoxylin and eosin (H\&E) stained sections of all cases were reviewed for confirmation of the diagnosis and grading [3].

For immunohistochemical staining, $5 \mu \mathrm{m}$ tick FFPE tissue sections were stained with mouse monoclonal antibodies for Arp2 (E12 dilution 1:50, Santa Cruz Biotechnology Inc. USA) and Arp3 (A1, 1:50 Santa Cruz Biotechnology Inc. USA) utilizing a standard streptavid in-biotin-peroxidase technique. Antigen retrieval was performed with EDTA/Tris buffer ( $\mathrm{pH}$ 9.0) in a microwave oven for 25 minutes. Positive controls were sections of colon cancer, while substitution of the primary antibodies by bovine serum of the same specificity served as a negative control.

Staining was graded according to the extent of positivity as follows: $(-),<5 \%$ positively stained cancer cells; $(+), 5 \%-30 \%$ positive cells; $(++), 30 \%-60 \%$ positive cells; and $(+++)>60 \%$ positive cells. Scoring was made by two observers, independently, and inter-observer discordances were resolved after common study of the slides in a multihead teaching microscope.

For statistical analysis the Fisher exact test was performed, with a value of $\mathrm{p}<$ 0.05 for statistical significance. Statistical evaluation was performed using Fisher's test to compare the positive or negative (binary) expression of Arp2 and Arp3 with the type and differentiation of OSCC (factor variable) forming consistency tables and we investigated as well the correlation between the expression of Arp2 and Arp3.

\section{Results}

The main clinical features of the cases studied are presented in Table 1. The age of the patients was 24 to 92 years (mean age 63 years, $\mathrm{SD}=17.42$ ); $55.68 \%$ were females and $42.04 \%$ were males. The most common primary sites were the tongue $(57.95 \%)$, followed by buccal mucosa (11.36\%) and gingiva (10.22\%). Microscopically, there were $9(10.22 \%)$ cases of verrucous carcinomas, $4(4.54 \%)$ of carcinoma in situ, 37 (42.04\%) of well differentiated OSCCs, 32 (36.36\%) of moderately differentiated OSCCs, and 6 (6.81\%) of poorly differentiated OSCCs.

Arp2 and Arp3 expression were cytoplasmic (Figure 1). Arp2 positivity was seen in $79(89.77 \%)$ cases and Arp3 positivity in 78 (88.63\%) cases (Table 2). In positive cases, Arp2 expression was graded as $(+)$ in $12.5 \%,(++)$ in $28.4 \%$ and $(+++)$ in $48.86 \%$ of the cases; Arp3 was graded as $(+)$ in $36.36 \%,(++)$ in $30.68 \%$ and $(+++)$ in $21.59 \%$ of the cases (Table 2 ). Both molecules were co-expressed in 78 cases and there was a statistical significant correlation between in the expression of Arp2 and Arp3 ( $\mathrm{p}$ < 0.05) (Table 3). Lymphocytes, neutrophils, macrophages, and vascular endothelial cells showed expression of Arp 2/3, as has been previously described in the stroma of malignant tumors [12] [15] [16] [17].

There was a tendency for increased expression of Arp2 and Arp 3 in invasive OSCC, compared to verrucous carcinomas (Figure 2) and carcinomas in situ 
Table 1. Main clinical features of 88 cases of OSCC.

\begin{tabular}{|c|c|}
\hline & No. of cases (\%) \\
\hline \multicolumn{2}{|l|}{ Gender } \\
\hline Female & $49(55.68)$ \\
\hline Male & $37(42.04)$ \\
\hline \multicolumn{2}{|l|}{ Primary site } \\
\hline Tongue & $51(57.95)$ \\
\hline Buccal mucosa & $10(11.36)$ \\
\hline Gingiva & $9(10.22)$ \\
\hline Lips & $8(9.09)$ \\
\hline Palate & $7(7.95)$ \\
\hline Floor of mouth & $3(3.40)$ \\
\hline \multicolumn{2}{|l|}{ Age (in years) } \\
\hline $20-30$ & $6(6.81)$ \\
\hline $30-40$ & $6(6.81)$ \\
\hline $40-50$ & $4(4.54)$ \\
\hline $50-60$ & $15(17.04)$ \\
\hline $60-70$ & $16(18.18)$ \\
\hline $70-80$ & $26(29.54)$ \\
\hline $80-90$ & $11(12.5)$ \\
\hline$>90$ & $2(2.27)$ \\
\hline
\end{tabular}

Table 2. Correlation of Arp2/Arp3 expression with tumor type.

\begin{tabular}{ccccc}
\hline & Verrucous (\%) & In situ c (\%) & OSCC (\%) & \\
\hline Arp2 & & & & TOTAL \\
+ & $0(0)$ & $2(2.27)$ & $9(10.2)$ & $11(12.5)$ \\
++ & $2(2.27)$ & $0(0)$ & $23(26.1)$ & $25(28.4)$ \\
+++ & $4(4.54)$ & $2(2.27)$ & $37(42)$ & $43(48.86)$ \\
0 & $3(3.4)$ & $0(0)$ & $6(6.8)$ & $9(10.22)$ \\
Total & $9(10.22)$ & $4(4.54)$ & $75(85.22)$ & $88(100)$ \\
p & $=0.11$ & $=0.13$ & $=0.27$ & \\
Arp3 & & & & TOTAL \\
+ & $4(4.54)$ & $2(2.27)$ & $26(29.5)$ & $32(36.36)$ \\
++ & $2(2.27)$ & $2(2.27)$ & $23(26.1)$ & $27(30.68)$ \\
+++ & $0(0)$ & $0(0)$ & $19(21.6)$ & $19(21.59)$ \\
$\mathbf{0}$ & $3(3.4)$ & $0(0)$ & $7(8)$ & $10(11.36)$ \\
Total & $9(10.22)$ & $4(4.54)$ & $75(85.22)$ & $88(100)$ \\
$\mathbf{P}$ & $\mathbf{0 . 0 5}$ & $\mathbf{0 . 7}$ & $\mathbf{0 . 0 8 9}$ & \\
\hline
\end{tabular}

OSCC $=$ oral squamous cell carcinoma. 
Table 3. Correlation of Arp2 and Arp3 expression in 88 OSCCs.

\begin{tabular}{cccccc}
\hline \multicolumn{7}{c}{ ARP3 } & \multicolumn{3}{c}{ TOTAL } \\
\hline ARP2 & $\mathbf{0}$ & + & ++ & +++ & \\
\hline $\mathbf{0}$ & $9(10.22 \%)$ & $0(0 \%)$ & $0(0 \%)$ & $0(0 \%)$ & $9(10.22 \%)$ \\
+ & $0(0 \%)$ & $5(5.68 \%)$ & $6(6.81 \%)$ & $0(0 \%)$ & $11(12.5 \%)$ \\
++ & $0(0 \%)$ & $18(20.45 \%)$ & $2(2.27 \%)$ & $5(5.68 \%)$ & $25(28.4 \%)$ \\
+++ & $1(1.13 \%)$ & $9(10.22 \%)$ & $19(21.59 \%)$ & $14(15.9 \%)$ & $43(48.86 \%)$ \\
TOTAL & $10(11.36 \%)$ & $32(36.36 \%)$ & $27(30.68 \%)$ & $19(21.59 \%)$ & $88(100 \%)$ \\
Fichers $\mathbf{p}$ & & & & & $0<0.05$ \\
\hline
\end{tabular}

OSCC $=$ oral squamous cell carcinoma.

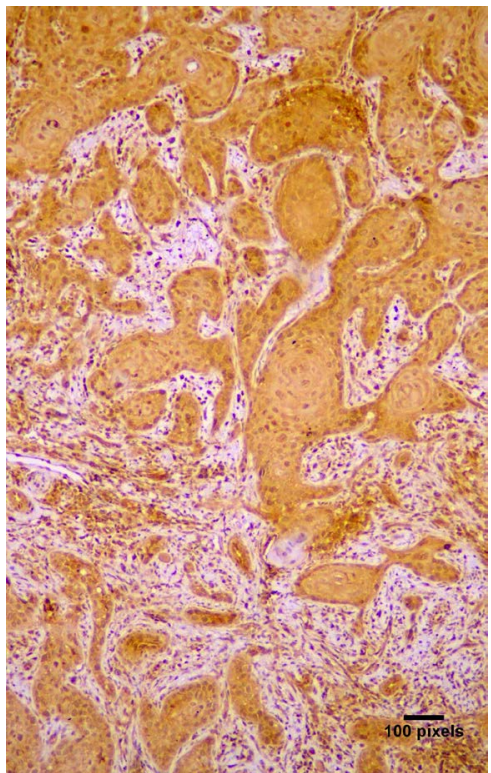

(a)

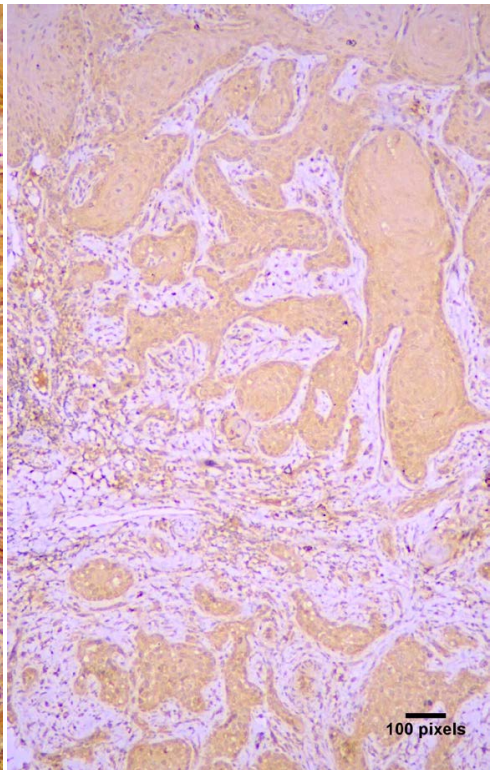

(b)

Figure 1. Cytoplasmic immunohistochemical expression of (a) Arp2 (+++) and (b) Arp3 $(++)$ in a moderately differentiated OSCC (streptavidin-biotin-peroxidase immunostaining, original magnification $\times 10$ ).

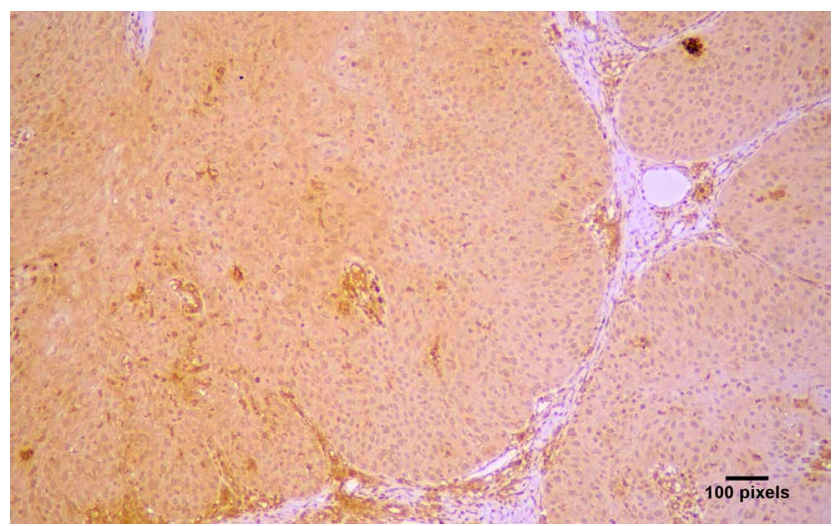

Figure 2. Immunohistochemical expression of Arp2 (+++) in a VSCC (streptavidin-biotin-peroxidase immunostaining, original magnification $\times 10$ ). 
(Figure 3), but this correlation was not statistically significant (Table 2). Finally, Arp2 and Arp3 expression was more common in well differentiated OSCC compared to moderate or poorly differentiated OSCC, but statistical significance between grade and expression was not seen (Table 4).

\section{Discussion}

In this study it was shown that Arp2 and Arp3 proteins were expressed in $89.7 \%$ and $88.6 \%$, respectively, of the 88 cases of OSCC examined. Arp2 and Arp3 expression in cancer cells was cytoplasmic as has been previously described [12]

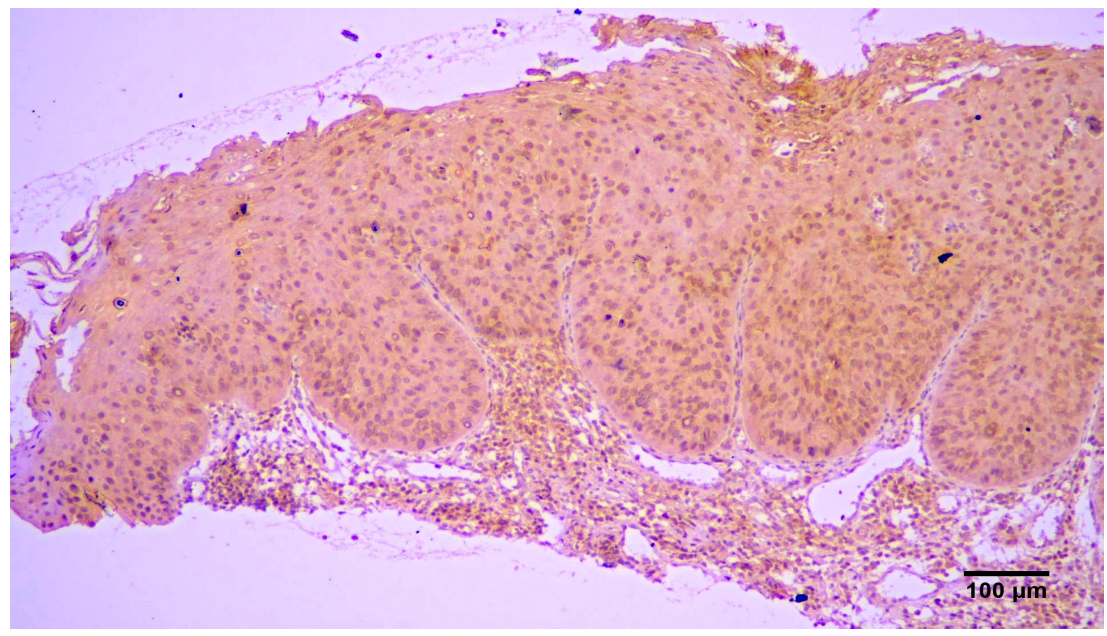

Figure 3. Immunohistochemical expression of Arp3 (+++) in a in situ carcinoma (streptavidin-biotin-peroxidase immunostaining, original magnification $\times 10$ ).

Table 4. Correlation of Arp2/Arp3 expression and histological grade in 75 OSCCs.

\begin{tabular}{|c|c|c|c|c|c|}
\hline \multirow{2}{*}{ Differentiation } & \multicolumn{4}{|c|}{ ARP2 (\%) } & \multirow{2}{*}{ Total } \\
\hline & 0 & + & ++ & +++ & \\
\hline High & $2(2.7 \%)$ & $5(6.7 \%)$ & $14(18.7 \%)$ & $16(21.3 \%)$ & $37(49.4 \%)$ \\
\hline Moderate & $2(2.7 \%)$ & $3(4 \%)$ & $7(9.3 \%)$ & $20(26.7 \%)$ & $32(42.7 \%)$ \\
\hline Poor & $2(2.7 \%)$ & $1(1.3 \%)$ & $2(2.27 \%)$ & $1(1.3 \%)$ & $6(8 \%)$ \\
\hline Total & $6(8 \%)$ & $9(12 \%)$ & $23(30.7 \%)$ & $37(49.3 \%)$ & $75(100 \%)$ \\
\hline \multicolumn{6}{|c|}{ Fisher's $\mathrm{p}=0.1$} \\
\hline \multirow{2}{*}{ Differentiation } & \multicolumn{4}{|c|}{ ARP3 (\%) } & \\
\hline & 0 & + & ++ & +++ & 10 tal \\
\hline High & $2(2.7 \%)$ & $14(18.7 \%)$ & $12(16 \%)$ & $9(12 \%)$ & 37 (49.4\%) \\
\hline Moderate & $3(4 \%)$ & $10(13.3 \%)$ & $9(12 \%)$ & $10(13.3 \%)$ & $32(42.6 \%)$ \\
\hline Poor & $2(2.7 \%)$ & $2(2.7 \%)$ & $2(2.7 \%)$ & $0(0 \%)$ & $6(8.1 \%)$ \\
\hline Total & $7(9.3 \%)$ & $26(34.7 \%)$ & $2(30.7 \%)$ & 19 (25.3\%) & 75 (100\%) \\
\hline
\end{tabular}

OSCC $=$ oral squamous cell carcinoma (75 out of 88 cases. In situ and verrucous carcinomas not included cause all high differentiated with no other histological grade). 
[14] [15] [16]. Immunohistochemistry is a reliable technique for the study of Arp2 and Arp3 expression and has been applied in cell cultures and FFPE tissues [11]-[18] [21].

Both proteins were co-expressed in 78 cases $(88.6 \%)$ and the statistical significant correlation between Arp2 and Arp3 expression seen in positive cases suggests formation of the Arp2/3 complex in those cells [12] [13] [15]. Formation of Arp2/3 complex is a prerequisite for the neoplastic cells to form filopodia, lamellipodia and invadopodia and acquire motility [4] [5] [22] and cells that express the Arp2/3 complex have greater ability for tissue movement [8] [22] [23] [24] [25]. Similar expression of Arp2/3 complex has been reported in gastric, colorectal, breast, lung, pancreatic and liver metastasis from colon carcinomas, as well as in gliomas [12]-[18].

Arp2 and Arp3 are more commonly expressed in invasive than in intramucosal carcinomas of the colon, as well as in gastric carcinomas than in intestinal metaplasia and gastritis [12] [13]. In various tumors Arp2/3 expression ispositively correlated to tumor size, depth of invasion, venous invasion and higher stage disease [13] [14] [15] [16] [17]. In colorectal adenocarcinomas Arp2/3 expression was higher in cases with liver metastasis and in moderately differentiated tumors [15] while ingliomas increased Arp2/3 expression was associated with higher stage disease and Arp2/3 upregulation was seen in migrating cells [17]. The immunohistochemical expression of ARPC2 was included in a multimarker diagnostic assay that was able to correctly distinguish melanomas from benign and atypical nevi [26]. Co-expression of Arp2 and Wave2, a member of the WASP protein family binding to Arp $2 / 3$ complex to form lamellipodial protrusions, was an independent risk factor for colorectal carcinoma with liver metastasis [15]. It was, also, detected more frequently in cases of lung carcinoma with lymph node metastasis and poor outcome [16], and was significantly different between invasive and not invasive carcinoma of the breast, and poor clinical outcome [14]. In the present study, Arp2/3 was more commonly expressed in invasive OSCC than in non-invasive verrucous carcinoma and carcinoma in $s i t u$, although this correlation was not found to be statistically significant, possibly due to small number of non-invasive cases included. The difference found in Arp3 expression between invasive OSCCs and verrucous carcinoma should be further examined, as it could be utilized in recognizing invasive cells in verrucous carcinoma.

In glioma cell cultures inhibition of the formation of Arp2/3 complex by CK666 leads to the disappearance of lamellipodia and significant inhibition of migration and invasive ability [17] [27]. In head and neck carcinoma cell silencing of ARPC5 genereduced the invasive potential [11], while in pancreatic cancer cell, silencing of any of the Arp2/3 complex subunits, in particular ARPC4, resulted in a significant decrease in cell migratory capacity [18]. Therefore, more information on Arp2/3 expression in OSCCs could indicate whether such inhibitors could be helpful in clinical practice.

The main shortcoming of our study is that the tumor stage and survival of the 
patients was not known, as the material consisted of diagnostic biopsies. Tumor grade in OSCCs may be associated to some extent with the biologic behavior of OSCC, but it is largely subjective. In addition, the number of cases of non-invasive verrucous carcinomas and carcinomas in situ was rather small for statistical conclusions to be reached.

In conclusion, expression of Arp2 and Arp3, indicative of the formation of the Arp $2 / 3$ complex, was seen in most OSCCs examined. Although no statistically significant correlation was found between the immunohistochemical expression of Arp2/Arp3 and tumor type or grade, the more common expression in invasive OSCCs than in non-invasive verrucous carcinomas and carcinomas in situ is indicative of its involvement in the infiltrative behaviour of the lesions.

\section{Conflicts of Interest}

The authors declare no conflicts of interest regarding the publication of this paper.

\section{References}

[1] Rivera, C. (2015) Essentials of Oral Cancer. International Journal of Clinical and Experimental Pathology, 8, 11884-11894.

[2] Hasegawa, T., Tanakura, M., Takeda, D., Sakakibara, A., Akashi, M., Minamikawa, T., et al. (2015) Risk Factors Associated with Distant Metastasis in Patients with Oralsquamous Cell Carcinoma. Otolaryngology_Head and Neck Surgery, 152, 1053-1060. https://doi.org/10.1177/0194599815580980

[3] Jerjes, W., Upile, T., Petrie, A., Riskalla, A., Hamdoon, Z., Vourvachis, M., et al. (2010) Clinicopathological Parameters, Recurrence, Locoregional and Distant Metastasis in 115 T1-T2 Oral Squamous Cell Carcinoma Patients. Head \& Neck Oncology, 2, 9. https://doi.org/10.1186/1758-3284-2-9

[4] Yamaguchi, H. and Condeelis, J. (2007) Regulation of the Actin Cytoskeleton in Cancer Cell Migration and Invasion. Biochimica et Biophysica Acta, 1773, 642-652. https://doi.org/10.1016/j.bbamcr.2006.07.001

[5] Alblazi, K.M. and Siar, C.H. (2015) Cellular Protrusions-Lamellipodia, Invadopodia and Podosomes-and Their Role in Progression of Orofacial Tumours: Current Understanding. Asian Pacific Journal of Cancer Prevention, 16, 2187-2191. https://doi.org/10.7314/APJCP.2015.16.6.2187

[6] Gross, S.R. (2013) Actin Binding Proteins: Their Ups and Downs in Metastatic Life. Cell Adhesion \& Migration, 7, 199-213. https://doi.org/10.4161/cam.23176

[7] Wu, C., Asokan, S.B., Berginski, M.E., Haynes, E.M., Sharpless, N.E., Griffith, J.D., et al. (2012) Arp2/3 Is Critical for Lamellipodia and Response to Extracellular Matrix Cues but Is Dispensable for Chemotaxis. Cell, 148, 973-987. https://doi.org/10.1016/j.cell.2011.12.034

[8] Yamaguchi, H. (2012) Pathological Roles of Invadopodia in Cancer Invasion and Metastasis. European Journal of Cell Biology, 91, 902-907. https://doi.org/10.1016/j.ejcb.2012.04.005

[9] Lai, F.P., Szczodrak, M., Block, J., Faix, J., Breitsprecher, D., Mannherz, H.G., et al. (2008) Arp2/3 Complex Interactions and Actin Network Turnover in Lamellipodia. EMBO Journal, 27, 982-992. https://doi.org/10.1038/emboj.2008.34 
[10] Suraneni, P., Rubinstein, B., Unruh, J.R., Durnin, M., Hanein, D. and Li, R. (2012) The Arp 2/3 Complex Is Required for Lamellipodia Extension and Directional Fibroblast Cell Migration. The Journal of Cell Biology, 197, 239-251. https://doi.org/10.1083/jcb.201112113

[11] Kinoshita, T., Nohata, N., Watanabe-Takano, H., Yoshino, H., Hidaka, H., et al. (2012) Actin-Related Protein 2/3 Complex Subunit 5(ARPC5) Contributes to Cell Migration and Invasion and Is Directly Regulated by Tumor-Suppressive MicroRNA-133a in Head and Neck Squamous Cell Carcinoma. International Journal of Oncology, 40, 1770-1778.

[12] Otsubo, T., Iwaya, K., Mukai, Y., Mizokami, Y., Serizawa, H., Matsuoka, T., et al. (2004) Involvement of Arp2/3 Complex in the Process of Colorectal Carcinogenesis. Modern Pathology, 17, 461-467.https://doi.org/10.1038/modpathol.3800062

[13] Zheng, H., Zheng, Y., Li, X., Takahashi, H., Hara, T., Masuda, S., et al. (2008) Arp2/3 Overexpression Contributed to Pathogenesis Growth and Invasion of Gastric Carcinoma. Anticancer Research, 28, 2225-2232.

[14] Iwaya, K., Norio, K. and Mukai, K. (2007) Coexpression of Arp2 and WAVE 2 Predicts Poor Outcome in Invasive Breast Carcinoma. Modern Pathology, 20, 339-343. https://doi.org/10.1038/modpathol.3800741

[15] Iwaya, K., Oikawa, K., Semba, S., Tsuchiya, B., Mukai, Y., Otsubo, T., et al. (2007) Correlation between Liver Metastasis of the Colocalization of Actin-Related Protein 2 and 3 Complex and WAVE2 in Colorectal Carcinoma. Cancer Science, 98, 992-999. https://doi.org/10.1111/j.1349-7006.2007.00488.x

[16] Semba, S., Iwaya, K., Matsubayashi, J., Serizawa, H., Kataba, H., Hirano, T., et al. (2006) Coexpression of Actin-Related Protein 2 and Wiskott-Aldrich Syndrome Family Verprolin-Homologous Protein2 in Adenocarcinoma of the Lung. Clinical Cancer Research, 12, 2449-2454. https://doi.org/10.1158/1078-0432.CCR-05-2566

[17] Liu, Z., Yang, X., Chen, C., Liu, B., Ren, B., Wang, L., et al. (2013) Expression of the Arp2/3 Complex in Human Gliomas and Its Role in the Migration and Invasion of Glioma Cells. Ongology Reports, 30, 2127-2136. https://doi.org/10.3892/or.2013.2669

[18] Rahuala, H., Teppo, S., Niemela, S. and Kallioniemi, A. (2013) Silencing of the Arp2/3 Complex Disturbs Pangreatic Cancer Cell Migration. Anticancer Research, $33,45-52$.

[19] Goley, E.D. and Welch, M.D. (2006) The Arp2/3 Complex: An Actin Nucleator Comes of Age. Nature Reviews Molecular Cell Biology, 7, 713-726. https://doi.org/10.1038/nrm2026

[20] Pollard, T.D. and Cooper, J.A. (2012) Actin, a Central Player in Cell Shape and Movement. Science, 326, 1208-1212. https://doi.org/10.1126/science.1175862

[21] Flanagan, L., Chou, J., Falet, H., Neujahr, R., Hartwing, J. and Stossel, T. (2001) Filamin A, the Arp2/3 Complex, and the Morphology and Function of Cortical Actin Filaments in Human Melanoma Cells. The Journal of Cell Biology, 155, 511-517. https://doi.org/10.1083/jcb.200105148

[22] Yamaguchi, H. and Oikawa, T. (2010) Membrane Lipids in Invadopodia and Podosomes: Key Structures for Cancer Invasion and Metastasis. Oncotarget, 1, 320-328.

[23] Kazazian, K., Go, C., Wu, H., Brashavitskaya, O., Xu, R., Dennis, J., et al. (2017) Plk4 Promotes Cancer Invasion and Metastasis through Arp2/3 Complex Regulation of the Actin Cytoskeleton. Cancer Research, 77, 434-447. https://doi.org/10.1158/0008-5472.CAN-16-2060 
[24] Giri, A., Bajpai, S., Trenton, N., Jayatilaka, H., Longmore, G.D. and Wirtz, D. (2013) The Arp2/3 Complex Mediates Multigeneration Dendritic Protrusions for Efficient 3-Dimensional Cancer Cell Migration. The FASEB Journal, 27, 4089-4099. https://doi.org/10.1096/fj.12-224352

[25] Nurnberg, A., Kitsing, T. and Grosse, R. (2011) Nucleating Actin for Invation. Nature Reviews Cancer, 11, 177-187. https://doi.org/10.1038/nrc3003

[26] Kashani-Sabet, M., Rangel, J., Torabian, S., Nosrati, M., Simko, J., et al. (2009) Aulti Marker Essay to Distinguish Malignant Melanoma from Benign Nevi. Proceedings of the National Academy of Sciences, 106, 6268-6272. https://doi.org/10.1073/pnas.0901185106

[27] Baggett, A.W., Cournia, Z., Han, M.S., Patargias, G., Glass, A.C., Liu, S.Y. and Nolen, B.J. (2012) Structural Characterization and Computer-Aided Optimization of a Small Molecule Inhibitor of Arp2/3 Complex, a Key Regulator of the Actin Cytoskeleton. ChemMedChem, 7, 1286-1294. https://doi.org/10.1002/cmdc.201200104 